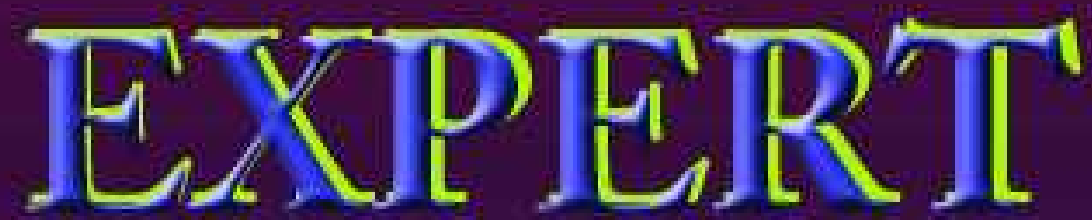

Jurnal Sistem Informasi

PENGEMBANGAN SISTEM APLIKASI LOKASI RUMAH KOST KABUPATEN PRINGSEWU BERBASIS WEB MOBILE

Elisabet Yunaeti Anggareni, Elieser Rudi HCN, Mad Muhaidi

KONSULTASI AKADEMIK BERBASIS ONLINE PROCESSING

Fenty Ariani, Robby Yuli Endra

PERENCANAAN ARSITEKTUR SISTEM INFORMASI MENGGUNAKAN MODEL ENTERPRISE ARCHITECTURE PLANNING (EAP)

di DIREKTORAT RESERSE KRIMINAL UMUM POLDA LAMPUNG

Hilda Dwi Yunita

DECISION SUPPORT SYSTEMMENGGUNAKAN METODE SAW DALAM MENENTUKAN KINERJA APARATUR PEMERINTAH KECAMATAN

M. Islam Mahdi, Rinawati, Tri Susilowati, Zul Kirom

PEMILIHAN CAFE TERBAIK MENGGUNAKAN METODE ANALYTICAL HIERARCHY PROCESS ( AHP)

Sti Ipnuwati, Khusnul Khotimah, Keni Puspita Sari

PEMETAAN COBIT 4.1 UNTUK PENILAIAN KEMATANGAN TATA KELOLA TI Yuthsi Aprilinda, Ayu Kartika Puspa

ISSN : 2088-5555 


\section{Expert}

Jurnal Manajemen Sistem Informasi dan Teknologi

Volume 08, Nomor 01, Juni 2018

\begin{tabular}{|l|l|}
\hline Judul & Hal \\
\hline $\begin{array}{l}\text { PENGEMBANGAN SISTEM APLIKASI LOKASI RUMAH } \\
\text { KOST KABUPATEN PRINGSEWU BERBASIS WEB MOBILE }\end{array}$ & $1-4$ \\
\hline $\begin{array}{l}\text { KONSULTASI AKADEMIK BERBASIS ONLINE } \\
\text { PROCESSING }\end{array}$ & $5-13$ \\
\hline $\begin{array}{l}\text { PERENCANAAN ARSITEKTUR SISTEM INFORMASI } \\
\text { MENGGUNAKAN MODEL ENTERPRISE ARCHITECTURE } \\
\text { PLANNING (EAP) di DIREKTORAT RESERSE KRIMINAL }\end{array}$ & $13-21$ \\
UMUM POLDA LAMPUNG & \\
\hline $\begin{array}{l}\text { DECISION SUPPORT SYSTEMMENGGUNAKAN METODE } \\
\text { SAW DALAM MENENTUKAN KINERJA APARATUR }\end{array}$ & $22-28$ \\
PEMERINTAH KECAMATAN & $29-38$ \\
\hline $\begin{array}{l}\text { PEMILIHAN CAFE TERBAIK MENGGUNAKAN METODE } \\
\text { ANALYTICAL HIERARCHY PROCESS AHP) }\end{array}$ & $39-48$ \\
\hline $\begin{array}{l}\text { PEMETAAN COBIT 4.1 UNTUK PENILAIAN } \\
\text { KEMATANGAN TATA KELOLA TI }\end{array}$ & \\
\hline
\end{tabular}

Fakultas Ilmu Komputer

Universitas Bandar Lampung

\begin{tabular}{|l|l|l|l|l|}
\hline JMSIT & Volume 08 & Nomor 01 & Lampung, Juni 2018 & ISSN 2088-5555 \\
\hline
\end{tabular}




\section{TIM PENYUNTING}

\section{Penanggung Jawab}

Ahmad Cucus, S.Kom., M.Kom.

Ketua Tim Redaksi:

Taqwan Thamrin, ST, M.Sc.

Penyunting Ahli (Mitra Bestari):

Mustofa Usman, Ph.D (Universitas Lampung)

Dra. Wamiliana, MA., Ph.D (Universitas Lampung)

Iing Lukman, M.Sc., Ph. D (Universitas Malahayati)

\section{Penyunting:}

Handri Santoso, M.Eng., Dr. Eng

Fenty Ariani, S.Kom, M.Kom

Robby Yuli Endra, S.Kom.,M.Kom

Ayu Kartika Puspa, S.Kom, M.TI

Erlangga, S.Kom, M.Kom

Pelaksana Teknis:

Wingky Kusuma, S.Kom

\section{Alamat Penerbit/Redaksi:}

Pusat Studi Teknologi Informasi

Fakultas Ilmu Komputer

Universitas Bandar Lampung

Gedung M Lt.2

Jl. ZA Pagar Alam No.89, Gedong Meneng, Rajabasa

Bandar Lampung

Email: jurnalfik@ubl.ac.id 


\title{
PENGEMBANGAN SISTEM APLIKASI LOKASI RUMAH KOST KABUPATEN PRINGSEWU BERBASIS WEB MOBILE
}

\author{
Elisabet Yunaeti Anggareni ${ }^{\sharp 1}$, Elieser Rudi HCN ${ }^{* 2}$, Mad Muhaidi ${ }^{\# 3}$ \\ ${ }^{123}$ STMIK Pringsewu Lampung \\ Jl. Wisma Rini No. 09 Pringsewu Lampung \\ Telp. (0729) 22240 website: www.stmikpringsewu.ac.id \\ elisabet.sugianto@yahoo.co.id \\ ${ }^{2}$ elieser.rudhy@gmail.com \\ ${ }^{3}$ muhaidiputralambar@yahoo.co.id
}

\begin{abstract}
Boarding house today is a promising business, this is because more and more people need a place to live. But in determining the location of boarding house is very difficult so that the need for an application system to solve the problem. This is what makes the author wants to design an application system location of boarding house Pringsewu District. Number of choice of location of boarding house in Pritsewu District then made an application that serves to determine the location of the right board for easier and faster. This system is a system that can help the community in determining the location of the boarding house as desired. With this application is expected to help the community in finding the location of suitable boarding house, especially in Pringsewu District. The method used in making this application is the method of observation.
\end{abstract}

Key Word: application, lodging house, mobile web

\section{PENDAHULUAN}

\subsection{Latar Belakang Masalah}

Sehubungan dengan semakin berkembangnya teknologi informasi, maka dengan sewajarnya akan memaksa masyarakat dalam memanfaatkan teknologi

tersebut dengan semaksimal mungkin dari segala segi kehidupan. Informasi tentunya bermacam-macam, salah satunya adalah untuk para mahasiswa yang akan menjalani studi tour ataupun menjalani kuliah ditempat yang jauh dari tempat tinggal.

Untuk itu jelas membuat mahasiswa tersebut harus segera mencari tempat tinggal sementara untuk dijadikan domisili mereka sampai studi selesai.

Mahasiswa tidak tahu wilayah kota dan tidak memiliki teman, itulah alasan kenapa sistem ini dibuat yang tujuannya tidak lain adalah untuk mempermudah mahasiswa dalam mencari tempat kost di kabupaten Pringsewu. Penulis juga merupakan mahasiswa yang pernah merasakan kebingungan saat mencari tempat kost yang pas dan ideal dan dengan harga yang sesuai, yang harus berkeliling wilayah Kabupaten Pringsewu untuk mencari lokasi tempat kost yang kosong dan sesuai.

Latar belakang tersebut memberikan inspirasi penulis membuat solusi untuk mempermudah para teman-teman mahasiswa untuk lebih mudah mencari tempat tinggal sementara, atau dengan kata lain Tempat Kost.
Untuk itu penulis mengambil judul "Sistem Aplikasi Lokasi Rumah Kost Kabupaten Pringsewu Berbasis Web Mobile."

\subsection{Rumusan Masalah}

Berdasarkan latar belakang masalah di atas, maka dapat dirumuskan masalah yang diambil dalam penelitian ini adalah bagaimana merancang sistem aplikasi lokasi rumah kost di kabupaten Pringsewu?

\subsection{Batasan Masalah}

Batasan masalah yang diambil secara umum dalam pembahasan ini adalah:

1. Sistem aplikasi ini hanya sebagai alat bantu bagi pihak yang akan mencari lokasi rumah kost yang sesuai dengan keinginan di Kabupaten Pringsewu.

2. Metode yang digunakan dalam perancangan sistem ini adalah metode observasi

\subsection{Tujuan Penelitian}

Tujuan dari penelitian ini adalah:

1. Merancang suatu sistem aplikasi lokasi rumah kost di Kabupaten Pringsewu.

2. Membantu masyarakat dalam menentukan lokasi rumah kost yang diinginkan di Wilayah Kabupaten Pringsewu.

\subsection{Manfaat Penelitian}

Manfaat dari penelitian ini adalah:

1. Membantu masyarakat dalam menentukan lokasi rumah kost di Kabupaten Pringsewu. 
2. Memudahkan dalam menentukan lokasi rumah kost di Kabupaten Pringsewu.

\section{TINJAUAN PUSTAKA}

\subsection{Aplikasi}

Nazrudin (2012: 9) berpendapat, perangkat lunak aplikasi adalah suatu subkelas perangkat lunak komputer yang memanfaatkan kemampuan komputer langsung untuk melakukan suatu tugas yang diinginkan pengguna.

Zaki (2013: 3) berpendapat, aplikasi merupakan komponen yang bermanfaat sebagai media untuk menjalankan pengolahan data ataupun berbagai kegiatan lainnya seperti pembuatan ataupun pengolahan dokumen dan file.

Widianti (2011: 2) berpendapat, aplikasi merupakan sebuah software (perangkat lunak) yang bertugas sebagai front end pada sebuah sistem yang dipakai untuk mengelolah berbagai macam data sehingga menjadi sebuah informasi yang bermanfaat untuk penggunanya dan juga sistem yang berkaitan.

Dari uraian di atas penulis menyimpulkan perangkat lunak aplikasi adalah suatu subkelas perangkat lunak komputer yang memanfaatkan kemampuan komputer langsung untuk melakukan suatu tugas yang diinginkan pengguna, sebuah software (perangkat lunak) yang bertugas sebagai front end pada sebuah sistem yang dipakai untuk mengelolah berbagai macam data sehingga menjadi sebuah informasi yang bermanfaat untuk penggunanya dan juga sistem yang berkaitan.

\subsection{Kost}

Rumah Kost adalah sebuah hunian yang dipergun akan oleh sebagian kelompok masyarakat sebagai tempat tinggal sementara atau sebuah hunian yang sengaja didirikan oleh pemilik untuk disewakan kepada beberapa orang dengan sist em pembayaran per bulan. (Abidin, 2012)

Menurut Pemerintah Atau Dinas Perumahan Rumah, kos dapat memiliki ciri-ciri atau diartikan sebagai berikut:

1. Perumahan pemondokan/rumah kost adalah rumah yang penggunaannya sebagian atau seluruhnya dijadikan sumber pendapatan oleh pemiliknya dengan jalan menerima penghuni pemondokan minimal 1 (satu) bulan dengan memungut uang pemondokan.

2. Pengelola rumah kost adalah pemilik perumahan dan atau orang yang mendapatkan dari pemilik untuk mengelola rumah kost.
3. Penghuni adalah penghuni yang menempati rumah kost sekurang-kurangnya 1 (satu) bulan dengan membayar uang pemondokan.

4. Uang Pemondokan/ kost adalah harga sewa dan biaya lainnya yang dibayar oleh penghuni dengan perjanjian.

Jasa kost atau indekost pada awalnya bukanlah jasa yang dipandang sebagai sumber pengahsilan atau bersifat bisnis, bahkan kebutuhan indekost pada awalnya tidak hanya sekedar untuk tinggal serumah dengan pemiliknya tapi sekaligus untuk "menitipkan" diri sehingga bisa mendapatkan pengalaman dan pendidikan mandiri.

Sejalan dengan perkembangan ekonomi dan sosial masyarakat, maka jasa kost sudah bergeser pada jasa penyewaan tempat/kamar dengan tidak perlu lagi serumah dengan pemilik. Fasilitas kost lebih ditekankan pada fasilitas fisik dan biaya yang dikenakan pada penyewa kost didasarkan pada kelengkapan fisik (sarana) serta letak strategis dari kost.

Di sisi lain, bertambahnya perguruan tinggi di Pringsewu memberikan dampak pada tumbuhnya usaha kost di sekitar kampus, semakin dekat dan lengkap fasilitas yang diberikan, semakin mahal biaya yang harus dibayar oleh mahasiswa.

Rumah kost merupakan tempat yang perlu juga diperhatikan oleh mahasiswa dan pengelola perguruan tinggi, karena suasana kost diyakini berpengaruh pada aktifitas mahasiswa saat di luar kampus seperti belajar, mengerjakan tugas, istirahat, dan kegiatan sosial lainnya.

\subsection{Mobile}

Agus (2012: 1) mengatakan, "Mobile dapat diartikan sebagai perpindahan yang mudah dari satu tempat ke tempat yang lain, misalnya telepon mobile berarti bahwa terminal telepon yang dapat berpindah dengan mudah dari satu tempat ke tempat lain tanpa terjadi pemutusan atau terputusnya komunikasi."

Setyadi dkk, (2013) mengatakan, "Sistem Aplikasi mobile merupakan aplikasi yang dapat digunakan walaupun pengguna berpindah dengan mudah dari satu tempat ketempat lain lain tanpa terjadi pemutusan atau terputusnya komunikasi. Aplikasi ini dapat diakses melalui perangkat nirkabel seperti pager, seperti telepon seluler dan PDA."

Buyens (2011: 2) mengatakan, "Aplikasi mobile berasal dari kata application dan mobile. Secara istilah aplikasi adalah program siap pakai yang direka untuk melaksanakan suatu fungsi bagi pengguna atau aplikasi yang lain dan dapat digunakan oleh sasaran yang dituju 
sedangkan mobile dapat diartikan sebagai perpindahan dari suatu tempat ke tempat yang lain.

\section{METODE PENELITIAN}

Metode yang digunakan adalah Metode Sistem Development Life Cycle (SDLC) yang berfokus pada metode sistem serta teknisi yang digunakan dalam membangun sebuah sistem. Tahapan-tahapan Sistem Development Life Cycle dalam sebuah aplikasi lokasi rumah kost.

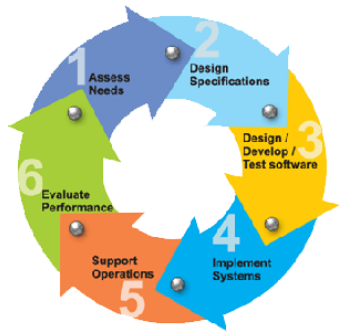

Gambar 1. Metode SDLC

\section{Planning}

Pada tahap ini penulis membuat perencanaan dengan mengumpulkan bahan serta study kelayakan kebutuhan aplikasi penjualan dan pembelian obat pada aplikasi lokasi rumah kost.

\section{Analisa}

Pada tahap ini penulis menganalisa seluruh kebutuhan sistem untuk usulan sistem aplikasi. Dengan menetapkan kemampuan yang diperlukan untuk kebutuhan informasi pengguna akhir, yang berguna untuk menyelesaikan tahap perancangan aplikasi penjualan.

\section{Desain}

Tahap ini dimodelkan informasi link dari setiap halaman, jika dalam sistem tersebut terdapat database maka digunakan tahap development dan database desain.

\section{Implementasi}

Penulisan program dan instalasi. Tahap penulisan program yang telah dianalisis dan didesain semua maka program yang digunakan adalah visual basic.

\section{Pemeliharaan Sistem}

Ada beberapa tahapan yang dilakukan oleh penulis yaitu :

- Memperbaiki desain yang error pada program aplikasi penjualan dan pembelian obat.

- Kemudian memodifikasi sistem untuk beradaptasi dengan perubahan lingkungan

- Menjaga sistem dari kemungkinan masalah di masa yang akan datang.

\section{IMPLEMENTASI \\ a. Halaman Depan}

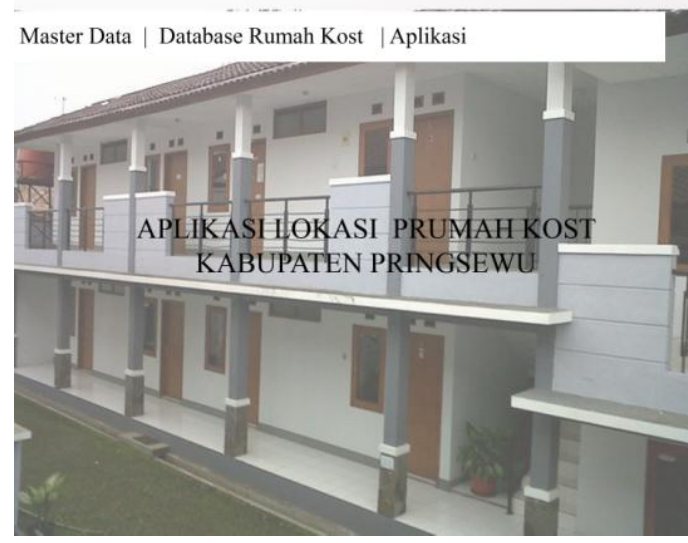

Gambar 1. Halaman Sistem aplikasi

\section{b. Halaman Harga Sewa Kost}

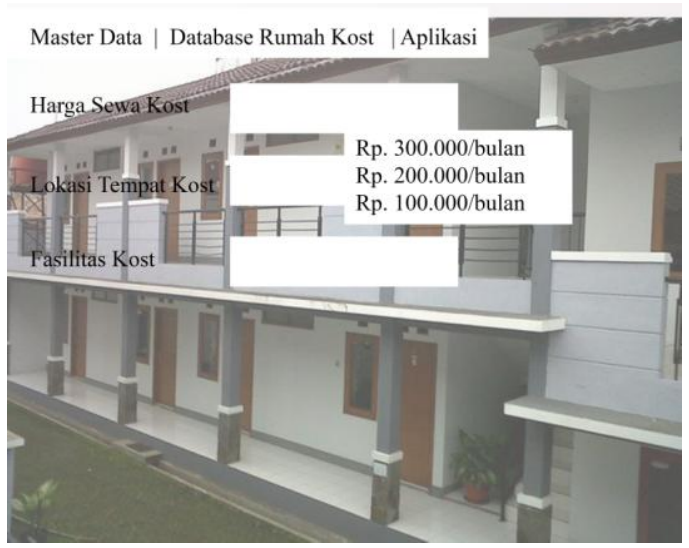

Gambar 2. Halaman Harga Sewa Kost

\section{c. Halaman Lokasi Tempat Kost}

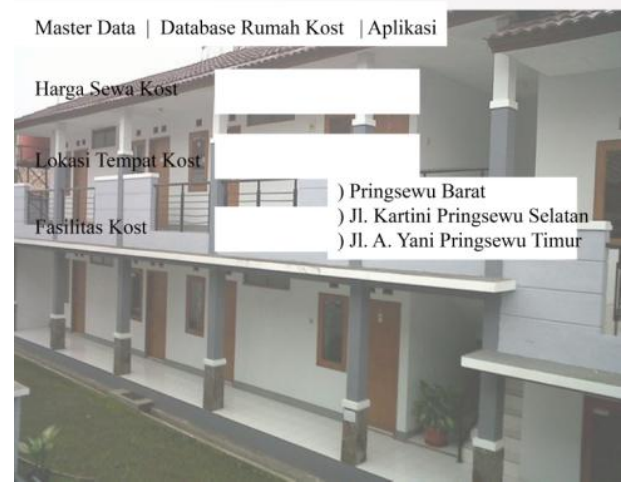

Gambar 3. Lokasi Tempat Kost 


\section{d. Halaman Fasilitas Kost}

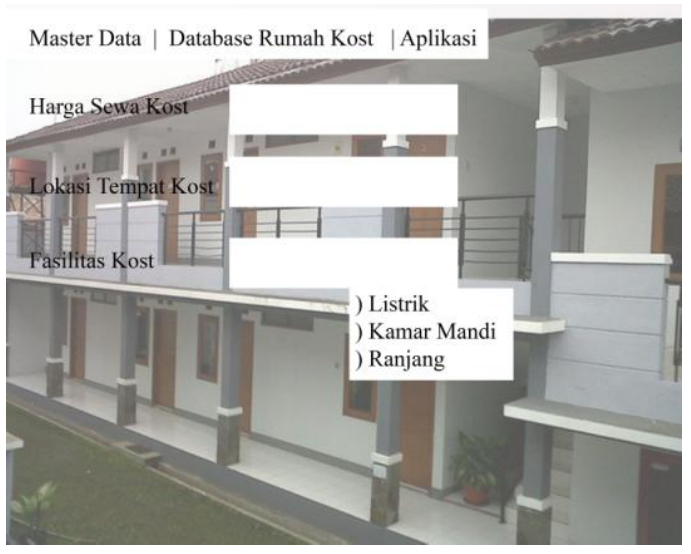

Gambar 4. Halaman Fasilitas Kost

\section{e. Halaman Hasil}

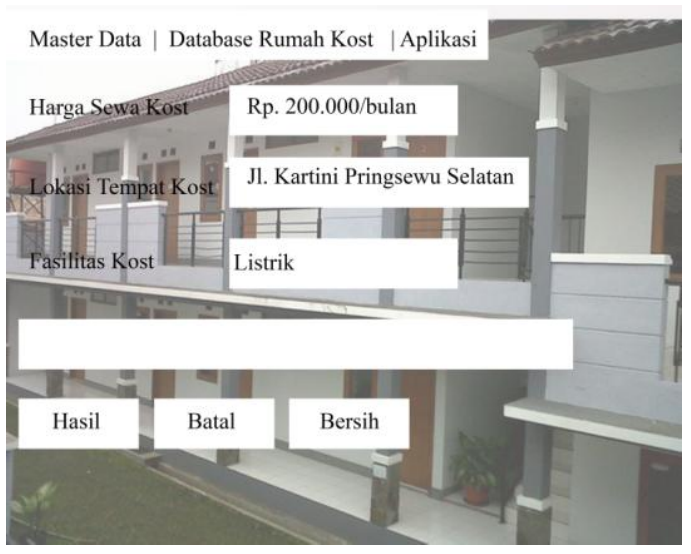

Gambar 5. Halaman Hasil

\section{PENUTUP}

\subsection{Kesimpulan}

Kesimpulan dari penelitian ini adalah Sistem aplikasi pemilihan lokasi rumah kost di Kabupaten Pringsewu menggunakan metode SDLC dengan bahasa pemrograman Visual Basic, dapat digunakan oleh masyarakat
Pringsewu pada khususnya dan pada masyarakat Lampung pada umumnya dalam memilih lokasi rumah kost di kabupaten Pringsewu.

\subsection{Saran}

Saran yang diberikan dari penelitian ini adalah

1. Dibutuhkan seorang yang ahli dalam bidang programer sehingga data dapat selalu di update.

2. Pengembangan sistem dapat dibuat dengan menggunakan program aplikasi yang lain seperti Borland Delpi, ataupun program website.

\section{DAFTAR PUSTAKA}

[1] Abidin. 2012. Sistem Informasi Rumah Kost Online Berbasis Web dan Messaging. Politeknik Elektronika Negeri. Surabaya

[2] Arman, Agus. 2012. Pengaruh Umur dan Ukuran Perusahaan, Reputasi Underwriter, dan Return On Equity Terhadap Tingkat Underpricing Saham Di Bursa Efek Indonesia. Makassar.

[3] Baridwan, Zaki. 2013. Sistem Informasi Akuntansi, edisi kedua. Yogyakarta: BPFE.

[4] Buyens, Jim. 2001. Web Database Development. Elex Media Komputindo. Jakarta

[5] Setyadi, Ary., \& Bhinuka, Galuh.(2013). Aplikasi pemesanan menu berbasis Android di Restoran Bumbu Desa Solo.

[6] Widianti. 2011. Koneksi Visual Basic dengan MySQL, http://rani-irsan. blogspot.com/ 2011/04/koneksi-visualbasic-6-vb6-mysql. html (diakses 22 Maret 2015). 
Redaksi :

Pusat Studi Teknologi Informasi (PSTI). Gedung Business Center Lt 2 J. Zainal Abidin No. 26 Bandar Lampung Telp. 0721 - 774626 g 772088555000

SistemInformasi@ubl.ac.id 